\title{
High-Temperature Rapid Devolatilization of Biomasses with Varying Degrees of Torrefaction
}

Jun Li ${ }^{1 *}$, Giorgio Bonvicini' ${ }^{2}$ Leonardo Tognotti ${ }^{2,3}$, Weihong Yang ${ }^{1}$, Wlodzimierz Blasiak ${ }^{1}$ Division of Energy and Furnace Technology, KTH-Royal Institute of Technology,

Brinellvägen 23, 10044 Stockholm, Sweden

Tel: +46 8 7908458; Fax: +46 82076 81; Email: jun2@kth.se

${ }^{2}$ International Flame Research Foundation, Via Salvatore Orlando 5, 57123 Livorno, Italy

${ }^{3}$ Dipartimento di Ingegneria Chimica, Universitá di Pisa, Via Diotisalvi 2, 56100 Pisa, Italy

\section{Abstract}

Torrefied biomass is a coal-like fuel that can be burned in biomass boilers or co-fired with coal in co-firing furnaces. To make quantitative predictions regarding combustion behaviour, devolatilization should be accurately described. In this work, the devolatilization of three torrefied biomasses and their parent material were tested in an Isothermal Plug Flow Reactor, which is able to rapidly heat the biomass particles to a maximum temperature of $1400{ }^{\circ} \mathrm{C}$ at a rate of $10^{4}{ }^{\circ} \mathrm{C} / \mathrm{s}$, similar to the conditions in actual power plant furnaces. During every devolatilization test, the devolatilized biomass particles were collected and analyzed to determine the weight loss based on the ash tracer method. According to the experimental results, it can be concluded that biomass decreases its reactivity after torrefaction, and the greater of torrefaction conducted, the lower the biomass reactivity. Furthermore, based on a two-competing-step model, the kinetic parameters were determined by minimizing the difference between the modeled and experimental results based on the least-squares objective function, and the predicted weight losses exhibited a good agreement with experimental data from biomass devolatilization, especially at high temperatures. It was also detected that $\mathrm{CO}$ and $\mathrm{H}_{2}$ are the primary components of the released volatile matters from the devolatilization of the three torrefied biomasses, in which $\mathrm{CO}$ accounts for approximately 45 to $60 \%$, and $\mathrm{H}_{2}$ accounts for 20 to $30 \%$ of the total volatile species.

Keywords: Rapid devolatilization; High temperature; Torrefied biomass; Kinetics. 


\section{Introduction}

Biomass has a large potential to act as major substitution of fossil fuels in the future because of its renewability and carbon-neutrality [1,2]. Unlike coal, the physical and chemical properties of biomass, such as a high moisture content, high volatile content, and low bulk density, complicate its transportation and processing. As a result, the large-scale application of biomass is limited [3].

To expand the thermal applications of biomass, a key challenge is to develop a conversion technology that allows biomass to compete with fossil fuels. Currently, pre-treatment process of torrefaction has shown its potential for upgrading biomass properties and therefore offers a possible solution [4]. Compared to raw biomass, torrefied biomass exhibits higher energy density, good grindability, higher flowability and uniformity [5-9]. Accordingly, many studies on biomass torrefaction have been reported. For example, the weight loss kinetics of biomass during torrefaction have been investigated [9], as well as the effects of the torrefaction conditions on the products and their chemical properties $[8,10]$. The grindability, reactivity and grinding energy consumption of torrefied biomass have also been investigated $[6,11]$.

Conventionally, fuel analyses are performed at relatively low temperatures $\left(<1000^{\circ} \mathrm{C}\right)$ and low heating rates $\left(<1^{\circ} \mathrm{C} / \mathrm{s}\right)$. However, when the biomass particles enter a pulverized-fuel flame, they are rapidly heated to a final temperature in the range of 1400 to $1600^{\circ} \mathrm{C}$ at a rate of approximately $10^{4}{ }^{\circ} \mathrm{C} / \mathrm{s}$. Early in 1977 , the high-temperature devolatilization of coals has been studied under rapid heating conditions was studied by Kobayashi et al., who found that the volatile yields increased significantly with high temperatures, and the high temperature volatile matters (HTVM) yields noticeably exceeded the standard volatile content that is given by standard proximate analysis, and thus, an empirical model of two-competing overall reactions was proposed for accurate prediction of HTVM yields[12, 13]. Later, a number of experimental 
studies on high temperature-rapid coal devolatilization were performed focusing on the yields of gaseous products and tar; the effects of particle size, oxygen coefficient and pressures; and model development [14-19].

Recently, studies of biomass devolatilization at high temperatures and high heating rates have also begun. Biagini et al. developed a satisfying method to study the size and morphology of biomass fuels and their chars after rapid devolatilization, with which the structural variations caused by the fast release of a high amount of volatile products can be evaluated [20]. Biagini et al. also characterized residues of biomass fuels after the initial devolatilization for their reactivity; and concluded that chars produced during the rapid pyrolysis were more reactive to oxidation than chars produced in medium conditions done by thermogravimetric balance [21]. Nora et al. investigated the influence of peak temperature $\left(500-1300{ }^{\circ} \mathrm{C}\right)$, heating rate $\left(600-1000{ }^{\circ} \mathrm{C} / \mathrm{s}\right)$ and hold time at peak temperature on devolatilization focusing on the fate of the main gaseous and nitrogen species [22]. Xiu et al. studied the devolatilization characteristics of biomasses during flash pyrolysis on a plasma-heated laminar entrained flow reactor with average heating rates of $10^{4}{ }^{\circ} \mathrm{C} / \mathrm{s}$; the corresponding kinetic parameters of the studied biomasses were determined and analyzed[23]. Jiménez et al. performed a complete set of devolatilization and combustion experiments with pulverized biomass in an entrained flow reactor under realistic combustion conditions, and the obtained experimental data were used to derive the kinetic parameters for best-fitting observed behaviors [24]. However, there is a general lack of quantitative information collected in reactors, which operate in conditions sufficiently close to the actual environments encountered in pulverized biomass combustion.

In large-scale applications, torrefied biomass is supposed to be a coal-like fuel that is eventually burned in biomass boilers or co-fired with coal in co-firing furnaces. Specifically, finding a suitable torrefaction degree of raw biomass for stable high-temperature devolatilization and combustion is critical because light torrefaction is always preferable for saving energy and shortening residence time. Moreover, to make quantitative predictions about combustion 
behavior, such as biomass thermal conversion, heat transfer, and pollutant formation, the hightemperature devolatilization should be accurately described because applying the kinetics obtained from low-heating-rate tests are not sufficiently reliable to make a precise prediction of volatile matter yields, gaseous products, and their releasing rates. In this work, the devolatilization of three torrefied biomasses and their parent fuel were studied experimentally in an isothermal plug flow reactor (IPFR), which is able to simulate conditions similar to those found in actual power plant furnaces. The effects of the degree of torrefaction on the devolatilization behaviors, apparent kinetics, and gaseous products of the studied biomasses were discussed.

\section{Experiments}

\subsection{Torrefaction facility}

In this study, a horizontal rotary furnace was used for biomass torrefaction. The rotating furnace is equipped with an electrical heating unit. To assure perfect thermal insulation, refractory fibers are used in the form of a ceramic blanket surrounding the inner tube. The rotational speed is changeable within the range of 2-12 rpm, and the tilt angle can be adjusted from horizontal up to $20^{\circ}$, which allows the selection of optimum conditions for process efficiency and residence time, as well as the elimination of material accumulation risk.

The studied biomass material is palm kernel shell (PKS). The original moisture content of PKS is in the range of $11-13 \%$, which is low compared to other biomass residues. PKS has a slightly higher heating value than average lignocelluloses biomass because it contains palm oil residue. In this study, the raw PKS was torrefied at temperatures of $200^{\circ} \mathrm{C}, 250^{\circ} \mathrm{C}$, and $300^{\circ} \mathrm{C}$ in the torrefaction furnace with the same residence time of 30 minutes, to produce solid products, three torrefied PKS materials with different degrees of torrefaction. To simplify, these three torrefied PKS materials are abbreviated as torrefied biomass \#1, \#2, and \#3, respectively. The torrefaction conditions are summarized in Table 1. 
$<$ Table $1>$

\subsection{IPFR reactor}

All devolatilization tests of biomasses were carried out in an IPFR reactor. The IPFR reactor is a $4 \mathrm{~m}$ long drop-tube reactor used to characterize solid fuels under conditions similar to those of real combustion applications with heating rates on $10^{4}-10^{5}{ }^{\circ} \mathrm{C} / \mathrm{s}$ and a maximum temperature of $1400^{\circ} \mathrm{C}$. The scheme of the IPFR reactor is shown in Figure 1: eight electrically heated modules are installed for furnace temperature adjustment, and each of them can be controlled independently. A K-tron solid fuel feeder is used to provide a continuous mass flow of approximately $100 \mathrm{~g} / \mathrm{h}$ of pulverized fuel, which is fed to the reactor through one of the 19 ports at different heights. The same ports can also be used to measure the flue gas temperature and chemical composition by using a suction pyrometer and gas-sampling probe. The chemical composition of the atmosphere entering the IPFR (mainly the oxygen concentration) can be changed by varying the different mass flows fed to the natural gas-fired pre-combustor located on the top of the IPFR. Once the velocity of the flue gases is fixed, the desired residence time of particles inside of the IPFR is achieved by changing the feeding port and the position of the sampling probe at the bottom of the reactor. The solid sampling probe consists of a water-cooled jacket where the collected particles are quenched with nitrogen in few milliseconds at a temperature below $300^{\circ} \mathrm{C}$ to stop all the reactions.

$<$ Figure 1 $>$

During each devolatilization test, the devolatilized biomass particles were collected and then analyzed to determine the mass conversion according to the ash tracer method, which assumes ashes to be inert and thermally stable. Eq. (1) was used to determine the weight loss on a dry-ash-free basis.

$$
X=1-\frac{a s h_{0}}{a s h}\left(\frac{1-a s h}{1-a s h_{0}}\right)
$$


In the IPFR, devolatilization tests were carried out under an almost oxygen-free atmosphere (with oxygen below 0.5\%), with a residence time between 30 and $1000 \mathrm{~ms}$. In this work, to fully understand the effects of torrefaction degree on biomass devolatilization behaviors, a total of 47 tests were carried out with varying devolatilization temperatures, residence times and biomass materials, as presented in Table 2 .

$<$ Table $2>$

\section{Results}

\subsection{Torrefaction products}

Prior to devolatilization studies, the three torrefied PKS materials (\#1, \#2, and \#3) together with their parent material, raw PKS, were ground in a cutting mill and then sieved to select particles in a size range of 62 to $105 \mu \mathrm{m}$. The proximate and ultimate analyses of four biomass samples were then performed using a standard programmed procedure, as shown in Table 3.

$<$ Table 3>

The torrefaction process can be evaluated by the degree of torrefaction, which is defined as the released volatiles divided by the initial volatile content of the raw material on dry-ash-free basis. Table 3 shows that a greater torrefaction caused a clear increase in torrefaction degree: when the raw PKS was torrefied at $300{ }^{\circ} \mathrm{C}$, the torrefaction degree increased to $28.21 \%$, meaning that $28.21 \%$ of volatile components were released during the torrefaction process. Simultaneously, the $\mathrm{O} / \mathrm{C}$ ratio decreased when increasing the torrefaction degree, meaning that the releasing rate of oxygen was faster than that of carbon during the torrefaction process. According to Tumuluru et al., the decarboxylation reactions of the acid groups in biomass dominated in lower temperatures, and therefore $\mathrm{CO}_{2}$ is a main component released during torrefaction process [25]. 


\subsection{Devolatilization}

The investigation of high heating rates and high-temperature devolatilization requires advanced facilities like the IPFR, which is able to give parameters that can be more suitable for practical applications than those obtained in traditional characterization. For example, the HTVM is higher than the volatile matter measured in proximate analysis. This is important especially for biofuel with a higher volatile matter content. IPFR tests are also useful to evaluate devolatilization kinetics at a high heating rate that can be significantly different from the kinetics obtained in a TG balance. Furthermore, the produced char particles can be reasonably more similar to those encountered in full-scale plants.

Prior to studying the devolatilization of torrefied biomasses, their parent material was investigated in the IPFR reactor, and the resulting weight loss trends are presented in Figure 2. In a short residence time, it can be clearly noticed that the temperature plays an important role in the devolatilization process. After $300 \mathrm{~ms}$ devolatilization tests at $900^{\circ} \mathrm{C}$ and $1200^{\circ} \mathrm{C}$, weight losses of $78.96 \%$ and $87.80 \%$ were respectively measured, this indicates a difference of approximately $10 \%$ attributable to the effect of temperature. In the early stage, the conversion at $900^{\circ} \mathrm{C}$ was higher than that at $1200^{\circ} \mathrm{C}$, which was most likely caused by the coalescence of pores and thermal annealing, resulting in the area and reaction rates decreases at the high temperature up to $1200^{\circ} \mathrm{C}$. This may also due to the experimental uncertainties associated with mass loss calculations based on the ash tracer method and the residence time; a more detailed discussion will be given in a later section of this paper.

$<$ Figure $2>$

To make a clear comparison, the torrefied biomass \#3, with greatest torrefaction degree, was selected to compare the weight loss between raw biomass and torrefied biomass. Figure 3 
shows the mass conversion of the selected torrefied biomass during the high-temperature and high-heating-rate devolatilization processes. Figure 3 also shows that the increased temperature significantly promotes weight loss in torrefied biomass. Furthermore, the devolatilization temperature also plays an important role in the final weight loss of torrefied biomass at the studied maximum residence time (1000 ms). Respectively, $12.2 \%, 37.0 \%$, and $47.4 \%$ of the original mass was released after $1 \mathrm{~s}$ high-heating-rate devolatilization at $500^{\circ} \mathrm{C}, 700^{\circ} \mathrm{C}$, and $900^{\circ} \mathrm{C}$. The final released volatiles at $900^{\circ} \mathrm{C}$ case was slightly lower than the standard volatile content based on the proximate analysis, while the final released volatiles at $500^{\circ} \mathrm{C}$ case was approximately $1 / 4$ of the standard volatile content.

Compared to raw PKS, the torrefied PKS material does not show any overlap of weight loss curves in the early devolatilization stage. This might be attributed to the release of hemicellulose during the torrefaction process, or to the fact that the particles are relatively clean compared to the raw biomass and can therefore avoid the coalescence of pores and thermal annealing in the subsequent devolatilization process. This could be a merit of torrefied biomass in further combustion. Furthermore, according to Figure 3, the temperature did not influence the high-temperature volatile matter (HTVM) in the rapid devolatilization of torrefied biomass \#3. The volatile yields were much higher than that the standard volatile content during raw material devolatilization; it may therefore be concluded that part some carbon was also released due to the high temperature condition.

$<$ Figure 3 $>$

\subsection{Devolatilization kinetics}

As mentioned above, the HTVM yield was higher than the standard volatile matter revealed by proximate analysis. The accurate prediction of the volatile matter yield as function of the temperature is thus important for combustion models. Two-competing-step model was employed to simulate devolatilization and predict the HTVM yields [12]. 
In the two-competing-step model, the first reaction $\left(A_{1}, E_{1}\right.$, and $\left.V_{1}\right)$ is used to calculate the devolatilization rate at low temperature, whereas the second reaction $\left(A_{2}, E_{2}\right.$, and $\left.V_{2}\right)$ plays a dominant role at higher temperatures. The aim of the IPFR devolatilization tests is to evaluate the HTVM yield in an oxygen free atmosphere and to elaborate global kinetics for torrefied biomasses. To determine these kinetic parameters, tests must be carried out at least at two different temperatures. The values of $\mathrm{V}_{1}$ and $\mathrm{V}_{2}$ are equal to the fraction of volatiles released during the proximate analysis and the highest temperature IPFR test, respectively. Finally, a fitting model and a target function must be fixed. In this study, the apparent kinetic parameters were determined by minimizing the residuals between the modeled and the experimental results according to a least-squares method.

Once the pre-exponential factors and activation energies are known, the model provides the rate of volatile evolution and volatile yields. The two kinetic rates are weighted to yield an expression for the devolatilization according to the following equation:

$$
\frac{m_{v}(t)}{m_{p, 0}}=\int_{0}^{t}\left(\alpha_{1} k_{1}+\alpha_{2} k_{2}\right) \cdot \exp \left(-\int_{0}^{t}\left(k_{1}+k_{2}\right) d t\right) d t
$$

where $m v(t)$ is the volatile yield over time $(\mathrm{kg}) ; m p, 0$ is the initial particle mass at injection on dryash-free basis $(\mathrm{kg})$; and the reaction rates $\left(\mathrm{k}_{1}\right.$ and $\left.\mathrm{k}_{2}\right)$ are expressed in Arrhenius form:

$$
k_{\mathrm{i}}=\mathrm{A}_{\mathrm{i}} \exp \left(-\frac{E_{i}}{R \cdot T_{p}}\right)
$$

In this work, the detailed devolatilization kinetics for the studied torrefied biomasses are given in Table 4. As described by Kobayashi [12], an important feature of the model is that $\mathrm{E}_{1}<\mathrm{E}_{2}$. The activation energy can be roughly used for estimating the reactivity of fuel: a fuel with lower activation energy normally shows a higher reactivity $[26,27]$. According to Table 4 , the activation energy $E_{1}$ increased when increasing the degree of torrefaction, meaning that the biomass exposed to deeper torrefaction requires more energy to initialize its devolatilization 
process. This is mainly caused by the rearrangement of biomass structures, due to the release of hemicellulose and the changing of cellulose structure during the torrefaction process. Compared to raw biomass, torrefaction biomass is characterised by anhydrous weight loss, a higher energy content and a lower reactivity [11], which are desired to form a stable flame during pulverizedfuel combustion.

$<$ Table 4>

\section{Discussions}

\subsection{Quantification of experimental uncertainties}

\subsubsection{Uncertainties of mass loss}

In this work, to determine the weight loss of biomass during high-temperature rapid devolatilization, the ash tracer method was used with the assumption that the ash of biofuel is inert and thermally stable during the tests. Thus, physical and chemical phenomena such as ash volatilization were not taken into account. This is a crucial issue when characterizing biomass devolatilization because of its low ash content. Therefore, it is crucial to evaluate the error affecting the experimental results in this work.

Two main sources of error can be identified: the uncertainty of the determination of the ash content (of both the parent biofuel and the collected samples), and the possible loss of ashes during the test. Eq. (4), Eq. (5), and Eq. (6) express the uncertainty of the calculated conversion as a function of the uncertainties on the two ash contents.

$$
\begin{aligned}
& E[X]=\left.\frac{\partial X}{\partial a \operatorname{sh}_{0}}\right|_{a \sin 0} \cdot E\left[a s h_{0}\right]+\left.\frac{\partial X}{\partial a s h}\right|_{a s h} \cdot E[a s h] \quad \text { Eq. (4) } \\
& \frac{\partial X}{\partial a h_{0}}=-\frac{1-a \operatorname{sh}}{a \sin \cdot\left(1-a h_{0}\right)^{2}} \quad \text { Eq. (5) } \\
& \begin{array}{ll}
\frac{\partial X}{\partial a s^{2}}=\frac{a h_{0}}{a \operatorname{sh}^{2} \cdot\left(1-a h_{0}\right)} \quad \text { Eq. (6) }
\end{array}
\end{aligned}
$$


The uncertainty of the initial ash content of the parent fuel and of the samples is determined by repeating at least five proximate analyses in a macro-TGA of both the parent fuel and the produced residuals.

Concerning another source of error, the conversion calculated with Eq. (1) can be correlated to the real one, expressed by Eq. (7), by introducing a coefficient $\alpha$, whose value is below unity because it corresponds to the ratio between the ashes remaining after the loss and the real ones, as expressed in Eq. (8).

$$
\begin{aligned}
& X_{\text {true }}=1-\frac{a s h_{0}}{a s h / \alpha} \cdot \frac{1-a s h_{\alpha}}{1-a s h_{0}} \quad(\alpha \leq 1) \\
& X_{\text {true }}=X \cdot \frac{\alpha \cdot\left(a s h-a s h_{0}\right)}{\alpha \cdot a s h-a s h_{0}}
\end{aligned}
$$

It is worth noting that the latter source of error affects the experimental results only as a positive error bar because the measured conversion can only be higher than the real value. On the other hand, the uncertainty of the ash content leads to an error that can be either positive or negative. The uncertainty of the ash content can be reduced by sieving the pulverized fuel into a narrow granulometry fraction and by increasing the number of proximate analysis repetitions.

\subsubsection{Uncertainties of residence time}

Concerning the high-temperature rapid devolatilization tests in the IPFR, two main sources of error may cause the uncertainties in the residence time. First, the sampling probe positioning accuracy has to be identified, which, during the experimental campaigns, was approximately 3-4 $\mathrm{mm}$. This positioning error can lead to an error of 1-2 $\mathrm{ms}$ on the residence time, depending on the flue gas velocity inside the reactor. A higher error occurs in an experimental test at a low flue gas velocity, whereas normally, a lower error might be expected when performing high temperature tests with a high flue gas velocity. 
Moreover, all the calculations used to determine the particles residence time are based on the measured mass flows. Normally, the main flow entering the IPFR has an accuracy of $2 \%$ for the air mass flow measurements; as a result, an average error of approximately $2 \%$ should also be considered for the residence time of particles.

\subsection{Comparison of mass losses of three torrefied biomasses}

Figures 4 shows the predicted mass loss trends for the three torrefied biomasses (\#1, \#2, and \#3) and their parent material by using the kinetics parameters of the two-competing-step model presented in Table 4, and compares these predictions with their corresponding experimental results. Here, it must be noted that the devolatilization tests of the three torrefied biomasses were performed at the temperatures of 500,700 , and $900{ }^{\circ} \mathrm{C}$, while the devolatilization tests of the parent biomass were carried out at the relatively elevated temperatures of 900 and $1200{ }^{\circ} \mathrm{C}$. To determine the kinetic parameters according to Kobayashi's model for the raw PKS, the first two points of the conversion measured at $900^{\circ} \mathrm{C}$ were excluded as shown in Figure 2 because the model is not able to predict the experimental overlap of the curves.

The modeled results showed a good agreement with the experimental results at relatively high temperatures, but the model underestimated the mass conversions at relatively low temperatures for the three torrefied materials. This may be because in low-temperature devolatilization, the first reaction occurs fast while the second reaction is negligibly slow. Furthermore, in rapid devolatilization at $900^{\circ} \mathrm{C}$, the weight loss of the parent material is much faster when compared to the torrefied biomasses. At a very short residence time of $30 \mathrm{~ms}$, 64.88\% mass of the raw PKS was released, while the mass release for the torrefied materials was less than $30 \%$ of their original weight. The order for the devolatilization rates of the four studied biomass materials was $r_{\mathrm{PKS}}>\mathrm{r}_{\mathrm{TPKS} \# 1}>\mathrm{r}_{\mathrm{TPKS} \# 2}>\mathrm{r}_{\mathrm{TPKS} \# 3}$; that is, the higher the volatile matter content of the biomass, the faster the complete volatile release in high temperature devolatilization processes. This conclusion if further supported by the weight loss curves at the intermediate 
temperature of $700{ }^{\circ} \mathrm{C}$. Furthermore, high temperature enhances the volatile release rate; for example, the weight loss curves become constant after $300 \mathrm{~ms}$ devolatilization at $900{ }^{\circ} \mathrm{C}$ for all cases, while weight loss ended after approximately $1 \mathrm{~s}$ when the devolatilization temperature was $700{ }^{\circ} \mathrm{C}$.

$<$ Figure 4 $>$

\subsection{High temperature volatile matter (HTVM)}

\subsubsection{Effects of heating rate on the release of volatiles}

Figure 5 plots the comparison of the amounts of volatiles released in rapid and slow devolatilization processes with the same final temperature, to understand the effects of heating rate on the yields of volatiles. Tests in the IPFR reactor were performed at a heating rate of $10^{4} \mathrm{C} / \mathrm{s}$ to a nominal reactor temperature of $900^{\circ} \mathrm{C}$, and the heating rate in the TG balance was kept slow at $0.3{ }^{\circ} \mathrm{C} / \mathrm{s}$ with a final temperature of $900{ }^{\circ} \mathrm{C}$ for comparison. It is widely accepted that hemicellulose is released in the biomass torrefaction at $200^{\circ} \mathrm{C}$, while the release of cellulose is highly dependent on the torrefaction temperature. Thus, the highly torrefied biomass (torrefied PKS \#3) contained less cellulose than the biomass exposed to light torrefaction (torrefied PKS \#1), and torrefied PKS \#2 had an intermediate cellulose content. As a consequence, the degree of torrefaction has a significant effect on the total volatile yields, which is independent of heating rate, as shown in Figure 5. Furthermore, the higher the heating rate is, the more volatile matters could be released. The amount of volatile matter released at a high heating rate is obviously greater than the standard volatile content obtained from proximate analysis, while the volatile matters released at a low heating rate approaches the standard volatile content. The residence time at the final temperature for all three torrefied biomasses was $1000 \mathrm{~ms}$, while only the HTVM data was available for raw biomass at a residence time of 500 ms. However, it is still obviously evident that the maximum increase in the volatile yields observed for parent biomass was $+17 \%$, 
which is much higher than that for the three studied torrefied materials: $+6 \%$ for torrefied PKS $\# 1,+12 \%$ for torrefied PKS \#2, and $+2 \%$ for torrefied PKS \#3.

$<$ Figure 5 $>$

\subsubsection{Effect of torrefaction degree on HTVM}

If the residence time is long enough, the volatile matter released at low-temperature devolatilization should approach the standard volatile content, as indicated by the dotted line in Figure 6. It is challenging to obtain the HTVM yield of biomass at high temperature, even when applying the ash tracer method. Because the ash content is very low for biomass, residuals collection after devolatilization is too sensitive to be controlled, and a very small uncertainty in the measured ash content could cause a large error in calculated HTVM yields. Thus, the calculated kinetic parameters of the two-competing-step model based on the experimental results either underestimate or overestimate the predicted yield of HTVM during devolatilization, as discussed in Section 4.1. Finally, the HTVM yields are summarized in Figure 6, to clarify the trend of HTVM yields during high temperature devolatilization.

Figure 6 clearly shows that when the volatile content of the studied biomass is higher than $50 \%$ on dry basis, the amount of volatile matters released during the high-temperature devolatilization process is greater than the standard volatile content of the biomass sample. Among the four studied biomass materials, the HTVM yield of torrefied PKS \#3 is almost equal to its standard volatile content. It is possible to extrapolate to the other end of the HTVM yield curve, at which the biomass is composed of $100 \%$ volatiles and the HTVM yields is therefore equal to the standard volatile content. Therefore, it is reasonable to identify a maximum difference between HTVM yield and standard volatile content for biomass materials with similar natures. The other extreme case supposes a biomass volatile content close to zero, in which the HTVM yield also equals to the standard volatile content because the volatile matters was 
previously removed during the pre-treatment processes. An extreme example of this situation is the biomass material that contains fully fixed carbon; little to no volatile matters could be released, even at high temperatures.

$<$ Figure 6>

\subsubsection{Gaseous species in volatiles}

Given that the HTVM yield is higher than the standard volatile content for most biomasses, it is relevant to analyze the released volatile components of torrefied biomasses during high-temperature devolatilization. In this work, gas speciation was determined during devolatilization tests in the IPFR reactor by means of on-line measurements with a micro-GC gas analyzer, which is able to detect $\mathrm{H}_{2}, \mathrm{CO}, \mathrm{CO}_{2}, \mathrm{CH}_{4}, \mathrm{C}_{2}\left(\mathrm{C}_{2} \mathrm{H}_{2}, \mathrm{C}_{2} \mathrm{H}_{4}\right.$, and $\left.\mathrm{C}_{2} \mathrm{H}_{6}\right)$, and the measured results are presented in Table 5. Obviously, $\mathrm{CO}$ and $\mathrm{H}_{2}$ are the main components of released volatile matters in the devolatilization of the three torrefied biomasses studied; in particular, $\mathrm{CO}$ accounts for approximately $45-60 \%$ and $\mathrm{H}_{2}$ for $20-30 \%$ of the total volatile species. Less relevant, $\mathrm{CH}_{4}$ and $\mathrm{CO}_{2}$ are in the ranges of $8-14 \%$ and $6-8 \%$, respectively. According to Neves et al., the heating rate has little effect on determining the composition of the pyrolysis gas[28], therefore, the results might also be useful for cases at low heating rates.

Within the lower temperature range of biomass pyrolysis (normally below $550^{\circ} \mathrm{C}$ ), $\mathrm{CO}_{2}$ and $\mathrm{CO}$ are major released gas species, followed by a small quantity of $\mathrm{CH}_{4}$ [28]. Compared to low temperature devolatilization, as temperature increases above $550^{\circ} \mathrm{C}$, the yields of combustible species $\left(\mathrm{CO}, \mathrm{H}_{2}\right.$, and $\left.\mathrm{CH}_{4}\right)$ become a strong function of temperature. In this study, when the devolatilization temperature reached $900^{\circ} \mathrm{C}$, the volume fractions of $\mathrm{CO}, \mathrm{H}_{2}$, and $\mathrm{CH}_{4}$ account for approximately $90 \%$ of the total released volatiles, while the $\mathrm{CO}_{2}$ yield becomes less than $8 \%$ because most $\mathrm{CO}_{2}$ was released during the torrefaction; the $\mathrm{CO}_{2}$ lost during torrefaction is attributed to the decarboxylation reactions of the acidic groups in the biomass. These behaviors 
could be related to the secondary decomposition of preliminary tar formed at lower temperature. When the biomass devolatilized at temperatures above $900{ }^{\circ} \mathrm{C}$, the secondary reactions of the volatiles become important.

$<$ Table 5>

\subsection{Effects of torrefaction degree on biomass devolatilization}

To understand the devolatilization properties of different biomasses, the hightemperature rapid devolatilization of torrefied biomasses with different torrefaction degrees was studied at $900^{\circ} \mathrm{C}$ in an IPFR reactor and compared to the behaviors of their parent material. The effect of torrefaction degree on weight loss at different residence times is shown in Figure 7. As expected, the amount of released volatiles drops linearly with increasing degree of torrefaction at a given residence time; results were calculated accurately at residence times of 300, 500, and 1000 ms, while relatively large error was evident at the residence time of $30 \mathrm{~ms}$. This might be because as the measurement uncertainty at a short residence time is more sensitive than that at relatively long residence time; as a result, the mass loss of the biomass with a torrefaction degree of $6.31 \%$ was less than that of biomasses with higher degrees of torrefaction. According to the discussions of residence time uncertainties in section 4.1.2, positioning error can lead to an error of 1-2 ms of the residence time, and thus the uncertainties of residence time can vary significantly from $0.1 \%$ in $1000 \mathrm{~ms}$ tests to $8 \%$ in $30 \mathrm{~ms}$ tests.

Furthermore, according to the Figure 7, it could be concluded that the linear relation between the weight loss properties of studied biomasses during high temperature-rapid devolatilization and their torrefaction degree is highly influenced by residence time. The differences in linear slope with varying residence time might correspond to the heating history and structural changes during high-temperature devolatilization, such as swelling, thermal annealing, and so on. More promisingly, there should be a relatively long residence time at which 
the weight loss of biomass is independent of its initial torrefaction degree, because the volatile matters would be completely released after a long period of devolatilization.

\section{Conclusions}

Torrefaction, a typical pre-treatment technology, has demonstrated its potential for upgrading biomass properties. Torrefied biomass is a coal-like fuel that can be burned in biomass boilers or co-fired with coal in co-firing furnaces. To make quantitative predictions of biomass combustion behaviors, devolatilization should be accurately described. In this work, devolatilization tests were conducted on three prepared torrefied biomasses and their parent material in an isothermal plug flow reactor, which can be rapidly heated to a uniform temperature in the range of 900 to $1400^{\circ} \mathrm{C}$ at a heating rate of $10^{4} \mathrm{C} / \mathrm{s}$, similar to the conditions in actual power plant furnaces. During every devolatilization test, the devolatilized biomass particles were collected and analyzed to determine the weight loss based on the ash tracer method. According to the experimental results, it can be concluded that biomass reactivity is reduced after torrefaction, and the greater the torrefaction, the lower the reactivity. Furthermore, based on a two-competing-step model, the kinetic parameters were determined by minimizing the residuals between the modeled and experimental results based on a least-squares objective function, and the predicted weight losses showed a good agreement with the experimental data from the biomass devolatilization tests, especially at high temperatures. It was also detected that $\mathrm{CO}$ and $\mathrm{H}_{2}$ were the major components of released volatiles in the studied devolatilization of the three torrefied biomasses; in particular, $\mathrm{CO}$ accounted for approximately 45 to $60 \%$ and $\mathrm{H}_{2}$ accounted for 20 to $30 \%$ of the total volatile species.

\section{Acknowledgments}

The authors would like to thank the EU-Biofuels Research Infrastructure for Sharing Knowledge (BRISK) project and EU/EIT-KIC Innoenergy for the financial support of this work. 
Author Jun Li also acknowledges the financial support from the China Scholarship Council (CSC).

\section{Symbol lists}

\section{Nomenclature}

$A_{i}$

$d_{p}$

$D_{0}$

$E_{i}$

$m_{v}(t)$

$m_{p, 0}$

$k_{1}$

$k_{2}$

$\mathrm{R}$

$T_{m}$

$V_{1}$

$V_{2}$

\section{Abbreviations}

$a_{s h}$

ash

daf

$d r y$

IPFR

FC

$\mathrm{VM}$

HTVM

Torrefied PKS \#1 Torrefied biomass ( PKS after 30 min torrefaction at $200{ }^{\circ} \mathrm{C}$ )

Torrefied PKS \#2 Torrefied biomass ( PKS after 30 min torrefaction at $250{ }^{\circ} \mathrm{C}$ )

Torrefied PKS \#3 Torrefied biomass ( PKS after 30 min torrefaction at $300^{\circ} \mathrm{C}$ )

PSD

$\mathrm{RB}$

PKS

Pre-exponential factor in Arrhenius expression, (1/s)

Particle diameter, $(\mathrm{m})$

Diffusion rate coefficient, $\left(\mathrm{m}^{2} / \mathrm{s}\right)$

Activation energy, $(\mathrm{J} / \mathrm{kmol})$

Volatile yield up to time, $(\mathrm{kg})$

Initial mass of biomass, $(\mathrm{kg})$

Devolatilization rate at low temperature range, $\left(\mathrm{kg} / \mathrm{m}^{2}-\mathrm{Pa}-\mathrm{s}\right)$

Devolatilization rate at high temperature range, $\left(\mathrm{kg} / \mathrm{m}^{2}-\mathrm{Pa}-\mathrm{s}\right)$

gas universal constant, $8.3143 \mathrm{~J} /(\mathrm{mol}-\mathrm{K})$;

mean particle and gas temperature $(\mathrm{K})$

Devolatilization stoichiometric coefficient for step 1 in Kobayashi Model, (-)

Devolatilization stoichiometric coefficient for step 2 in Kobayashi Model, (-)

Initial ash content of biomass, (wt. \%)

Ash content of residue, (wt. \%)

Dry ash free basis

Dry basis

Isothermal Plug Flow Reactor

Fixed carbon

Volatile matter

High temperature volatile matter

Particle size distribution

Raw biomass

Palm Kernel Shell, the parent material of torrefied biomasses 


\section{References}

1. Werther, J., et al., Combustion of agricultural residues. Progress in Energy and Combustion Science, 2000. 26(1): p. 1-27.

2. Zhang, L., C. Xu, and P. Champagne, Overview of recent advances in thermo-chemical conversion of biomass. Energy Conversion and Management, 2010. 51(5): p. 969-982.

3. Biagini, E., F. Barontini, and L. Tognotti, Devolatilization of Biomass Fuels and Biomass Components Studied by TG/FTIR Technique. Industrial \& Engineering Chemistry Research, 2006. 45(13): p. 4486-4493.

4. van der Stelt, M.J.C., et al., Biomass upgrading by torrefaction for the production of biofuels: A review. Biomass and Bioenergy, 2011. 35(9): p. 3748-3762.

5. Hakkou, M., et al., Investigations of the reasons for fungal durability of heat-treated beech wood. Polymer Degradation and Stability, 2006. 91(2): p. 393-397.

6. Arias, B., et al., Influence of torrefaction on the grindability and reactivity of woody biomass. Fuel Processing Technology, 2008. 89(2): p. 169-175.

7. P. Bergman, A.B., R. Zwart and J. Kiel, Torrefaction for biomass co-firing in existing coal-fired power stations. ENC-C-05-013, 2005.

8. Prins, M.J., K.J. Ptasinski, and F.J.J.G. Janssen, Torrefaction of wood: Part 2. Analysis of products. Journal of Analytical and Applied Pyrolysis, 2006. 77(1): p. 35-40.

9. Prins, M.J., K.J. Ptasinski, and F.J.J.G. Janssen, Torrefaction of wood: Part 1. Weight loss kinetics. Journal of Analytical and Applied Pyrolysis, 2006. 77(1): p. 28-34.

10. Couhert, C., S. Salvador, and J.M. Commandré, Impact of torrefaction on syngas production from wood. Fuel, 2009. 88(11): p. 2286-2290.

11. Repellin, V., et al., Energy requirement for fine grinding of torrefied wood. Biomass and Bioenergy, 2010. 34(7): p. 923-930.

12. Kobayashi, H., J.B. Howard, and A.F. Sarofim, Coal devolatilization at high temperatures. Symposium (International) on Combustion, 1977. 16(1): p. 411-425.

13. Anthony, D.B., et al., Rapid devolatilization of pulverized coal. Symposium (International) on Combustion, 1975. 15(1): p. 1303-1317.

14. Sørensen, L.H., O. Biede, and R.E. Peck, An experimental study of high-temperature, oxidative pulverized coal devolatilization. Symposium (International) on Combustion, 1994. 25(1): p. 475-483.

15. Tyler, R.J., Flash pyrolysis of coals. 1. Devolatilization of a Victorian brown coal in a small fluidized-bed reactor. Fuel, 1979. 58(9): p. 680-686.

16. Cliff, D.I., et al., Products from rapid heating of a brown coal in the temperature range 400$2300{ }^{\circ} \mathrm{C}$. Fuel, 1984. 63(3): p. 394-400.

17. Jess, A., Mechanisms and kinetics of thermal reactions of aromatic hydrocarbons from pyrolysis of solid fuels. Fuel, 1996. 75(12): p. 1441-1448.

18. Niksa, S., et al., On the role of heating rate in rapid coal devolatilization. Symposium (International) on Combustion, 1985. 20(1): p. 1445-1453.

19. Yan, B.-H., et al., Experimental investigation on coal devolatilization at high temperatures with different heating rates. Fuel, (0).

20. Biagini, E., P. Narducci, and L. Tognotti, Size and structural characterization of lignin-cellulosic fuels after the rapid devolatilization. Fuel, 2008. 87(2): p. 177-186.

21. Biagini, E., M. Simone, and L. Tognotti, Characterization of high heating rate chars of biomass fuels. Proceedings of the Combustion Institute, 2009. 32(2): p. 2043-2050.

22. Di Nola, G., W. de Jong, and H. Spliethoff, The fate of main gaseous and nitrogen species during fast heating rate devolatilization of coal and secondary fuels using a heated wire mesh reactor. Fuel Processing Technology, 2009. 90(3): p. 388-395.

23. Shuangning, X., et al., Devolatilization characteristics of biomass at flash heating rate. Fuel, 2006. 85(5-6): p. 664-670. 
24. Jiménez, S., et al., Kinetics of devolatilization and oxidation of a pulverized biomass in an entrained flow reactor under realistic combustion conditions. Combustion and Flame, 2008. 152(4): p. 588-603.

25. Shankar TumuluruJaya, S., HessJ. Richard, WrightChristopher T., and BoardmanRichard D.. , A review on biomass torrefaction process and product properties for energy applications. Industrial Biotechnology, 2011. 7(5): p. 384-401.

26. Cumming, J.W., Reactivity assessment of coals via a weighted mean activation energy. Fuel, 1984. 63(10): p. 1436-1440.

27. El-Samed, A.K.A., et al., Variation of char reactivity during simultaneous devolatilization and combustion of coals in a drop-tube reactor. Fuel, 1990. 69(8): p. 1029-1036.

28. Neves, D., et al., Characterization and prediction of biomass pyrolysis products. Progress in Energy and Combustion Science, 2011. 37(5): p. 611-630. 


\section{Tables}

Table 1. Conditions applied for biomass torrefaction

\begin{tabular}{lccc}
\hline & Parent material & $\begin{array}{c}\text { Temperature } \\
\left({ }^{\circ} \mathbf{C}\right)\end{array}$ & $\begin{array}{c}\text { Residence time } \\
(\mathbf{m i n})\end{array}$ \\
\hline Torrefied PKS \#1 & raw PKS & 200 & 30 \\
Torrefied PKS \#2 & raw PKS & 250 & 30 \\
Torrefied PKS \#3 & raw PKS & 300 & 30 \\
\hline
\end{tabular}

Table 2. Devolatilization tests

\begin{tabular}{|c|c|c|c|c|c|c|c|}
\hline \multirow{2}{*}{ Temperature $\left({ }^{\circ} \mathrm{C}\right)$} & \multicolumn{7}{|c|}{ Residence time (ms) } \\
\hline & 30 & 50 & 100 & 150 & 300 & 500 & 1000 \\
\hline \multirow[t]{3}{*}{500} & - & - & TPKS \#1 & - & TPKS \#1 & - & TPKS \#1 \\
\hline & TPKS \#2 & & TPKS \#2 & & TPKS \#2 & & TPKS \#2 \\
\hline & TPKS \#3 & & TPKS \#3 & & TPKS \#3 & & TPKS \#3 \\
\hline \multirow[t]{3}{*}{700} & TPKS \#1 & - & TPKS \#1 & - & TPKS \#1 & - & TPKS \#1 \\
\hline & TPKS \#2 & & TPKS \#2 & & TPKS \#2 & & TPKS \#2 \\
\hline & TPKS \#3 & & TPKS \#3 & & TPKS \#3 & & TPKS \#3 \\
\hline \multirow[t]{4}{*}{900} & raw PKS & raw PKS & Raw PKS & raw $\mathrm{PKS}$ & Raw PKS & raw PKS & - \\
\hline & TPKS \#1 & & TPKS \#1 & & TPKS \#1 & & TPKS \#1 \\
\hline & TPKS \#2 & & TPKS \#2 & & TPKS \#2 & & TPKS \#2 \\
\hline & TPKS \#3 & & TPKS \#3 & & TPKS \#3 & & TPKS \#3 \\
\hline 1200 & raw $\mathrm{PKS}$ & raw PKS & Raw PKS & raw $\mathrm{PKS}$ & Raw PKS & raw $\mathrm{PKS}$ & - \\
\hline
\end{tabular}

Note: "TPKS" is the abbreviation of torrefied PKS.

Table 3. Analysis of pulverized biomass powder

\begin{tabular}{|c|c|c|c|c|c|c|c|c|c|c|c|}
\hline & \multicolumn{4}{|c|}{ Proximate analysis, $w t \%$} & \multicolumn{4}{|c|}{ Ultimate analysis, $\mathrm{wt}^{0} \%$} & \multirow{2}{*}{$\begin{array}{c}\text { Torrefaction } \\
\text { degree } \\
(\%, \text { daf })\end{array}$} & \multirow{2}{*}{$\begin{array}{l}O / C \\
(d r y)\end{array}$} & \multirow{2}{*}{$\begin{array}{l}L H / k g \\
M V^{d b}\end{array}$} \\
\hline & $M C^{a r}$ & $V M^{d b}$ & $F C^{d b}$ & $A s h^{d b}$ & $C^{d b}$ & $H^{d b}$ & $O^{d b}$ & $\boldsymbol{N}^{d b}$ & & & \\
\hline raw PKS & 7.20 & 72.78 & 22.99 & 4.23 & 51.83 & 6.28 & 37.03 & 0.44 & 0 & 0.54 & 17.28 \\
\hline Torrefied PKS \#1 & 5.80 & 66.53 & 26.91 & 6.56 & 54.30 & 5.07 & 33.52 & 0.50 & 6.31 & 0.46 & 20.90 \\
\hline Torrefied PKS \#2 & 5.60 & 61.87 & 30.82 & 7.31 & 55.43 & 4.90 & 31.83 & 0.50 & 12.17 & 0.43 & 20.50 \\
\hline Torrefied PKS \#3 & 5.10 & 49.92 & 41.58 & 8.50 & 60.67 & 4.33 & 25.90 & 0.57 & 28.21 & 0.32 & 25.00 \\
\hline
\end{tabular}


Table 4. Devolatilization kinetics of the biomasses with different degrees of torrefaction

\begin{tabular}{|c|c|c|c|c|c|c|c|}
\hline $\begin{array}{l}\text { Biomass } \\
\text { samples }\end{array}$ & $\begin{array}{c}A_{1} \\
\left(s^{-1}\right)\end{array}$ & $\begin{array}{c}A_{2} \\
\left(s^{-1}\right)\end{array}$ & $\begin{array}{c}\mathrm{E}_{1} \\
(\mathrm{~kJ} / \mathrm{mol})\end{array}$ & $\begin{array}{c}\mathrm{E}_{2} \\
(\mathrm{~kJ} / \mathrm{mol})\end{array}$ & $\mathbf{V}_{1}$ & $\mathbf{V}_{2}$ & $\begin{array}{c}\text { Mean error } \\
(\%)\end{array}$ \\
\hline raw PKS & $6.20 \mathrm{E}+02$ & $8.00 \mathrm{E}+04$ & 42.5 & 130 & 0.860 & 0.960 & 4.5 \\
\hline Torrefied PKS \#1 & $6.40 \mathrm{E}+03$ & $1.98 \mathrm{E}+05$ & 57.0 & 145 & 0.665 & 0.74 & 4.5 \\
\hline Torrefied PKS \#2 & $5.48 \mathrm{E}+03$ & $2.15 \mathrm{E}+07$ & 59.8 & 147 & 0.619 & 0.70 & 4.5 \\
\hline Torrefied PKS \#3 & $3.27 \mathrm{E}+03$ & $2.10 \mathrm{E}+07$ & 60.2 & 159 & 0.499 & 0.50 & 4.5 \\
\hline
\end{tabular}

${ }^{*}$ calculated as the mean of the absolute differences between the modeled and experimental results of the studied biomasses from

the high-temperature rapid devolatilization tests in the IPFR: error $=\sum_{n} \frac{\left|X_{\bmod }-X_{\exp }\right|}{n} \cdot 100 \%$

Table 5. Detected gas species (vol. \%) during $900^{\circ} \mathrm{C}$ devolatilization

\begin{tabular}{ccccccc}
\hline & \multicolumn{5}{c}{ Detected gases species (vol. \%) } \\
\cline { 2 - 7 } & $\mathbf{C O}$ & $\mathbf{H}_{\mathbf{2}}$ & $\mathbf{C H}_{\mathbf{4}}$ & $\mathbf{C O}_{\mathbf{2}}$ & $\mathbf{C}_{\mathbf{2}} \mathbf{H}_{\mathbf{4}}$ & $\mathbf{C}_{\mathbf{2}} \mathbf{H}_{\mathbf{2}}$ \\
\hline Torrefied PKS \#1 & 47.79 & 25.44 & 13.52 & 6.45 & 4.32 & 2.46 \\
Torrefied PKS \#2 & 45.50 & 27.99 & 13.58 & 6.14 & 4.44 & 2.41 \\
Torrefied PKS \#3 & 58.19 & 21.60 & 8.38 & 7.86 & 2.84 & 1.15 \\
\hline
\end{tabular}

\section{Figure captions}

Figure 1. Scheme of the IPFR reactor

Figure 2. Comparison of weight losses of raw PKS at two different devolatilization temperatures

Figure 3. Comparison of weight losses of torrefied PKS \#3 at three different devolatilization temperatures

Figure 4. Devolatilization properties of biomasses with varying degrees of torrefaction

Figure 5. Comparison of the volatile matter released in rapid and slow devolatilization processes

Figure 6. HTVM yields of different fuels with varying volatile contents

Figure 7. Weight loss curves of four biomass materials during devolatilization at $900^{\circ} \mathrm{C}$ 